\title{
Endowment effects? "Even" with half a million on the table!
}

Blavatskyy, Pavlo ; Pogrebna, Ganna

\begin{abstract}
In the television show Deal or No Deal, a contestant is endowed with a sealed box containing a monetary prize between one cent and half a million euros. In the course of the show, the contestant is offered to exchange her box for another sealed box with the same distribution of possible monetary prizes inside. This offers a unique natural experiment for studying endowment effects under high monetary incentives. We find evidence of only a weak endowment effect when contestants exchange their box for another box with the same distribution of possible prizes
\end{abstract}

DOI: https://doi.org/10.1007/s11238-009-9152-4

Posted at the Zurich Open Repository and Archive, University of Zurich

ZORA URL: https://doi.org/10.5167/uzh-156455

Journal Article

Published Version

Originally published at:

Blavatskyy, Pavlo; Pogrebna, Ganna (2010). Endowment effects? "Even" with half a million on the table! Theory and Decision, 68(1-2):173-192.

DOI: https://doi.org/10.1007/s11238-009-9152-4 


\title{
Endowment effects? "Even" with half a million on the table!
}

\author{
Pavlo Blavatskyy • Ganna Pogrebna
}

\begin{abstract}
In the television show Deal or No Deal, a contestant is endowed with a sealed box containing a monetary prize between one cent and half a million euros. In the course of the show, the contestant is offered to exchange her box for another sealed box with the same distribution of possible monetary prizes inside. This offers a unique natural experiment for studying endowment effects under high monetary incentives. We find evidence of only a weak endowment effect when contestants exchange their box for another box with the same distribution of possible prizes.
\end{abstract}

Keywords Endowment effect · Expected utility theory · Prospect theory · Television show

\section{Introduction}

Substantial experimental evidence from economics and psychology suggests that initial endowments have an impact on human preferences. Endowment effect (Thaler 1980) says that when people come to own a good, they tend to value it more than they did before they owned it (Kahneman et al. 1991). For example, Kahneman et al. (1990) find that students, who were given mugs worth $\$ 6$ each, were willing to sell them at a median price of $\$ 7$ each. At the same time, students, who did not come to

Previous version of this paper was circulated under the title "Loss Aversion? Not with Half a Million on the Table!".

\footnotetext{
P. Blavatskyy $(\varangle)$

Institute for Empirical Research in Economics, University of Zurich, Winterthurerstrasse 30, 8006 Zurich, Switzerland

e-mail: pavlo.blavatskyy@iew.unizh.ch

G. Pogrebna

Institute for Social and Economic Research and Policy, Columbia University, International Affairs Building 420 West 118th Street, 3355, New York, NY 10027, USA
} 
possess the mugs, were willing to buy them at a median price of $\$ 3.50$ per mug. While many experiments replicate this result, several studies treat the endowment effect as an inexperienced consumer's mistake, which disappears in the process of learning (e.g., Knez et al. 1985; Coursey et al. 1987; Brookshire and Coursey 1987; Shogren 1994).

In a field experiment, List (2004) finds that professional dealers on the sports card market are more likely to accept the swap offer than inexperienced consumers. List (2004) argues that consumers facing decision problem which they have experienced before may overcome the endowment effect. In a similar vein, Myagkov and Plott (1997) find that risk-seeking behavior over losses predicted by prospect theory tends to decrease with experience in a market setting. Plott and Zeiler (2007) show that asymmetries in exchange behavior disappear if an experimenter controls for subject misconceptions by introducing incentive-compatible elicitation device, subject training in the task, paid practice rounds, and subject anonymity. This article contributes to this literature by showing that individuals exhibit only weak endowment effects if they make decisions involving high stakes (even without prior practice or training and when their decisions are broadcasted on television).

We use a natural experiment of the television show Deal or No Deal to analyze endowment effects when stakes are large. Deal or No Deal is produced by the media company Endemol in 44 countries worldwide. In this article, we analyze French, Italian, and British versions of the show. Deal or No Deal contestants are endowed with a sealed box, containing an unknown monetary prize. The maximum prize is $€ 500,000$ in France and Italy and $£ 250,000$ in the UK.

During the show, contestants have a possibility to exchange their box for another box with the same distribution of possible prizes inside. ${ }^{1}$ This provides a unique natural experiment to test endowment effects in a previously unexplored domain-when lotteries involve large outcomes. The importance of large stakes is apparent in Blavatskyy and Pogrebna (2008) who find that in contrast to numerous laboratory studies with low monetary incentives, British and Italian Deal or No Deal contestants do not exhibit lower risk aversion when facing gains of low probability.

We find that in all the three versions of the show, Deal or No Deal contestants exhibit only weak endowment effects. The swap offer is accepted by $73 \%, 47 \%$, and $43 \%$ of the contestants who receive exchange offers in the French, Italian, and British version of the show, respectively. This finding suggests that people may overcome endowment effects under high monetary incentives.

The remainder of this article is organized as follows. Section 2 describes television show Deal or No Deal. Data are presented in Sect. 3. Section 4 derives the theoretical predictions of expected utility, regret, and prospect theory. Section 5 presents our main empirical findings. Section 6 concludes.

\section{Description of the television show}

French, Italian, and British versions of the Deal or No Deal television show have the following common features. Several contestants, each representing one of the

1 In addition to exchange offers, contestants also receive monetary offers for selling the content of their box. 
administrative regions of the country, participate in every television episode. All the contestants self-select into the show by submitting an application for participation either through the national Deal or No Deal web site or by calling the selection center in their country.

Contestants are randomly assigned identical sealed boxes, numbered consecutively from the first to the last. Boxes contain monetary prizes, ranging from very small to very large. Monetary prizes are allocated across boxes by the independent notary company. Contestants know the list of possible prizes at any point of the show, but they do not know the content of each box.

The show consists of two stages. During the first (preliminary) stage, one contestant is selected to play the game. Remaining contestants (waiting contestants) continue to participate in the next television episode. The contestant, selected to play the game, is replaced by a new representative of the same region. New contestant is selected from a pool of volunteers who applied for the participation.

The second stage is the game itself. During the game, a contestant keeps her own box and opens the remaining boxes one by one. When a box is opened, the prize hidden inside is publicly revealed and eliminated from the list of possible prizes.

After opening several boxes, a contestant receives an offer from the "bank." The offer could be either a monetary price for the content of her box or the possibility to exchange her box for any of the remaining sealed boxes. If a contestant is offered to swap her box, she can pick any box from the sealed boxes that are left in the game (the new box is not selected by the producers, the audience, or other contestants). In this article, we analyze contestants' decisions whether to accept or reject the exchange offer.

The game terminates when either the contestant accepts the price offered by the "bank" or when all boxes are opened. In the latter case, the contestant leaves with the content of her box, which is opened last. The game does not terminate when the contestant accepts (or rejects) the exchange offer. Irrespective of the contestant's decision on the exchange offer, she must continue opening the remaining sealed boxes one by one until the "bank" makes another offer or all the boxes are opened.

\subsection{French version}

À Prendre ou à Laisser is the French version of Deal or No Deal. It is aired every weeknight on the channel TF1 of the French television. The show features 22 contestants from 22 different regions of France, holding identical boxes. Each box contains a randomly assigned monetary prize, ranging between $€ 0.01$ and $€ 500,000$. $^{2}$ The list of possible prizes is given on Fig. 1. For entertainment purposes, three low monetary prizes are substituted by token gifts (e.g., a cup for $€ 5$ or a puppy for $€ 100$ ). Boxes are assigned to the contestants by an independent adjudicator who is present in the studio during the show.

During the preliminary stage, contestants receive one general knowledge selection question with three possible answers (A, B, and C). One contestant out of those, who

2 In 2007, the number of contestants was increased to 24 , and the top prize was raised to $€ 1,000,000$. 


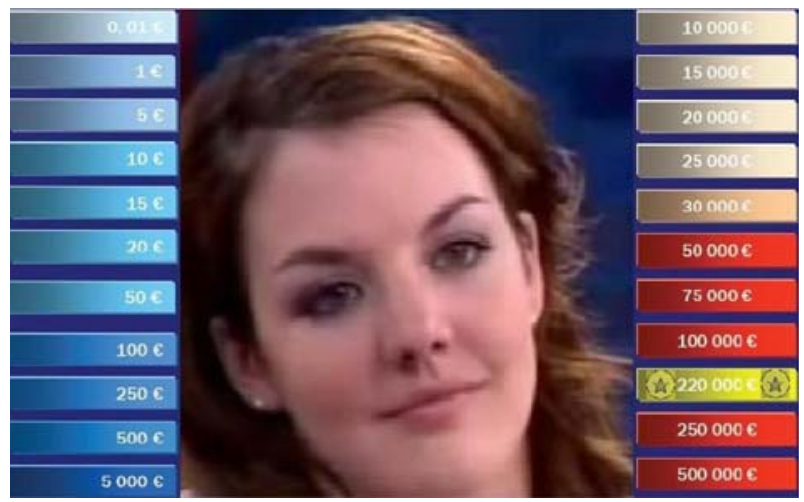

Fig. 1 Screenshot with a list of possible prizes in the French version of Deal or No Deal

have answered this question correctly, is selected to play the game. However, the criteria for the selection procedure (e.g., "fastest finger," random selection, longest waiting time on the show) are not revealed to the public.

In the French version of Deal or No Deal, one of the prizes is a "Joker"-an episode-specific variable. The "Joker" is determined in the beginning of the show by multiplying the number of correct answers with the selection question, given by the contestants in the preliminary stage, by $€ 10,000$. The amount of the "Joker" is instantaneously added to the list of possible prizes. ${ }^{3}$

In the French version of the show, contestants receive offers from the "bank" after opening 6, 3, 3, 3, 3, and 2 boxes, respectively. Another peculiarity of this version is that exchange offers are fairly frequent (up to four exchange offers per episode). However, there is no requirement for the "bank" to make any exchange offers to the contestant during a television episode.

\subsection{Italian version}

Affari Tuoi is a daily television show, broadcasted on the first channel of Italian television RAI Uno. Twenty contestants participate in every episode. Every contestant is randomly assigned one box that contains 1 of 20 monetary prizes ranging between $€ 0.01$ and $€ 500,000$ (Fig. 2). Four low prizes are substituted with the token gifts. Similarly to the French version, independent notary company assigns boxes to contestants. Before February 11, 2006, contestants have received offers from the "bank" after opening 6, 3, 3, 3, and 3 boxes, respectively. Starting from February 11, 2006, the "bank" makes offers after a contestant opens $3,3,3,3,3,1,1$, and 1 box, respectively.

In every episode, the contestant receives at least one offer to exchange her box. Official rules of the show require the "bank" to offer exchange option at least once in every television episode. Therefore, the first offer that the "bank" makes to the contestant

\footnotetext{
3 In our example, 22 contestants have answered the selection question correctly. Therefore, the amount of the "Joker" displayed on Fig. 1 is $€ 220,000$.
} 


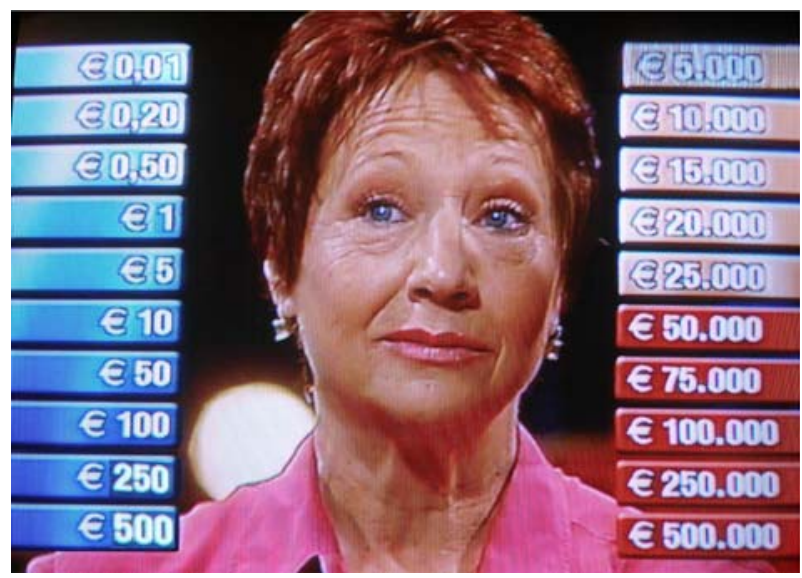

Fig. 2 Screenshot with a list of possible prizes in the Italian version of Deal or No Deal

is always the exchange offer. ${ }^{4}$ Since the "bank" always proposes exchange in the first offer, irrespective of the distribution of the remaining prizes or the personality of the contestant, the first exchange offer is always uninformative, i.e., it does not provide any information about possible content of the contestant's box. ${ }^{5}$

Occasionally (in $28 \%$ of all the episodes in our sample), the contestant also receives the second offer to exchange her box. The "bank" typically offers the second exchange opportunity when there are only two sealed boxes left (including the box in the possession of the contestant). ${ }^{6}$ The second exchange offer is made at the discretion of the "bank" (official rules of the show do not regulate when the "bank" should offer second exchange possibility). However, in our recorded sample, the "bank" offers the second exchange option almost equally frequently when the prize inside the contestant's box is above and below the median of the distribution of possible prizes. Thus, the second exchange offer is uninformative, i.e., the contestants cannot infer new information about the prize hidden inside their box upon observing the second exchange offer.

\subsection{British version}

Deal or No Deal UK is aired on Channel 4 of the British television. Twenty two contestants from different parts of the UK participate in every episode. ${ }^{7}$ Prizes range

\footnotetext{
4 Before February 11, 2006, the first offer has always been made after the contestant opened six boxes. Starting from February 11, 2006, the first offer is made after the contestant opened three boxes.

5 According to Bombardini and Trebbi (2005), the "bank" in the Italian version of Deal or No Deal is informed about the prize sealed inside the contestant's box and can potentially make informative offers.

6 Such offers constitute $71 \%$ of all the cases when the "bank" proposes the second exchange opportunity. In $18 \%(7 \%)$ of the cases, the second exchange offer is made when five (eight) unopened boxes are left. In one episode, exchange is offered when four unopened boxes are left.

7 Except for the British contestants, contestants from India, Italy, and the United States appeared on the show. In contrast to the French and Italian version, in the British version, regional diversity is not strictly observed, i.e., several representatives of the same administrative region may appear on the show at one time.
} 


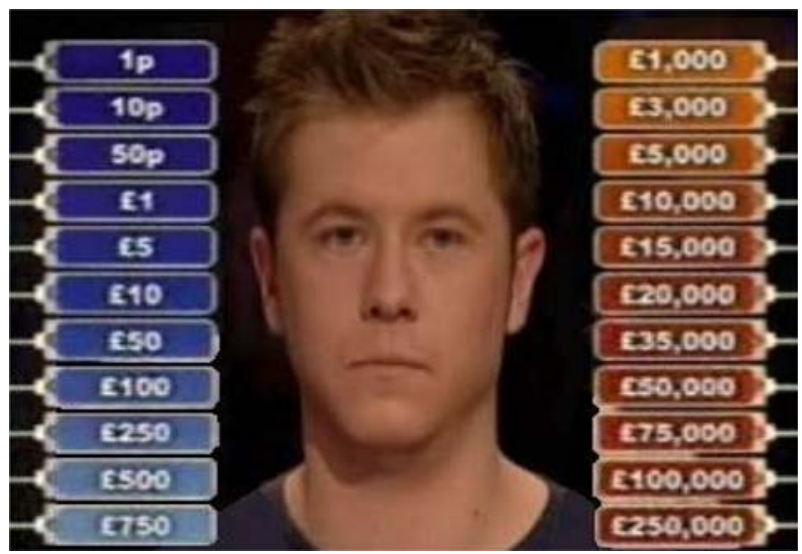

Fig. 3 Screenshot with a list of possible prizes in the British version of Deal or No Deal

between $£ 0.01$ and $£ 250,000$ (Fig. 3). ${ }^{8}$ They are randomly assigned to 22 boxes by an independent adjudicator. However, an independent adjudicator does not assign boxes to contestants. After the prizes are distributed across boxes and boxes are sealed, contestants choose their boxes at random by drawing numbered ping-pong balls.

The British version of the show does not have a selection phase. The contestant is pre-selected by the producers, and therefore, it is quite rare for contestants to wait for more than 30 shows before they receive an opportunity to play the game. However, waiting contestants do not know in advance when they are going to be selected.

The game itself follows a similar procedure as in France and Italy: contestants receive offers after opening 5, 3, 3, 3, 3, and 3 boxes, respectively. However, there are three major differences. First, the contestants in Deal or No Deal UK rarely receive exchange offers. As a rule, the "bank" offers to exchange the box when there are only two unopened boxes left and the contestant rejects the last monetary offer. ${ }^{9}$

Second, in Deal or No Deal UK, the contestant may take advice from waiting contestants or suggestions from the host about the next box to be opened or about whether to accept or reject the deal from the "bank." This is very different from the procedure in France and Italy where it is observed by the representative of the independent notary company, present on the show, that contestant's decision to open a certain box or to accept or reject the monetary offer of the "bank" is not precipitated by the suggestions of waiting contestants or the host. Moreover, while in Deal or No Deal $U K$ the contestant is allowed to change her mind about opening a certain box after she has already called out its number, in France and Italy contestants do not have this opportunity.

\footnotetext{
8 At the time of the broadcasts, the exchange rate was $£ 1=€ 1.48$.

9 Such offers constitute $78 \%$ of all the exchange offers in our Deal or No Deal UK dataset. In $21 \%$ of all the cases, the first offer is the exchange offer. In one episode, exchange is offered when eight unopened boxes are left.
} 


\section{Data}

The data set, analyzed in this article, consists of 49 television episodes of the French version, 100 episodes of the Italian version, and 355 episodes of the British version of Deal or No Deal. Only one contestant plays the game in every episode. French episodes have been broadcasted from January 3, 2006 till April 10, 2006 on channel TF1. ${ }^{10}$ Italian episodes have been aired from September 20, 2005 to February 13, 2006 on channel RAI Uno. ${ }^{11}$ British episodes have been broadcasted from October 31 , 2005 to January 12, 2007 on Channel 4 of the British television. ${ }^{12}$ Table 1 summarizes selected descriptive statistics for French, Italian, and British contestants in our data set.

Deal or No Deal regulations state that prizes are allocated across boxes at random. We have checked whether prizes are equally likely to appear inside each box. In our data set, the distribution of prizes across boxes is not significantly different from a uniform distribution at 1\% significance level (e.g., Figs. 4 and 5 for Affari Tuoi). Thus, there is no apparent reason for misconceptions that large prizes are more likely to be inside particular boxes.

\section{Theoretical prediction}

Expected utility theory and many generalized non-expected utility theories such as, for example, regret theory predict that an individual is exactly indifferent between keeping her own box and exchanging it for any of the remaining identical sealed boxes. However, (cumulative) prospect theory predicts that an individual should always reject the exchange offer due to the assumption of loss aversion. First, we derive these theoretical predictions for a static decision problem when contestants evaluate a risky lottery as a lottery that delivers each of the possible prizes (that have not yet been eliminated from the game) with equal probability. Then, we consider a dynamic case, when contestants evaluate a risky lottery taking into account the expectation of future "bank" offers that they will receive in the course of the game.

\subsection{Static decision problem}

\subsubsection{Expected utility theory}

According to expected utility theory, an individual should be exactly indifferent between keeping her box and exchanging it for any of the remaining sealed boxes.

\footnotetext{
10 French episodes have been recorded by Professor Anabela Botelho who generously shared the data with us.

11 Italian episodes have been recorded by the authors.

12 A significant portion of the British data has been compiled from http://donduk.blogspot.com/2006/06/ previous-game-reports.html and related Internet sources. We have also watched several episodes, available online, including the Hall of Fame editions of the show with Deal or No Deal UK highlights. We are particularly grateful to Dave Woollin for collecting show statistics and publishing it on http://www. screwthebanker.com and to Morten Lau for providing information on the personal characteristics of the contestants.
} 
Table 1 Selected descriptive statistics for French, Italian, and British contestants

\begin{tabular}{llll}
\hline Descriptive statistics & French version & Italian version & British version \\
\hline Percent of female & $71 \%$ & $55 \%$ & $50 \%$ \\
Average age (years) & 28 & 47 & 41 \\
Percent of married & $39 \%$ & $81 \%$ & $51 \%$ \\
Average earnings & $€ 71,579$ & $€ 30,363$ & $£ 16,763$ \\
Median earnings & $€ 50,000$ & $€ 20,000$ & $£ 12,900$ \\
Average number of exchange & 1.86 & 1.29 & 0.18 \\
$\quad$ offers per contestant & & & \\
\hline
\end{tabular}
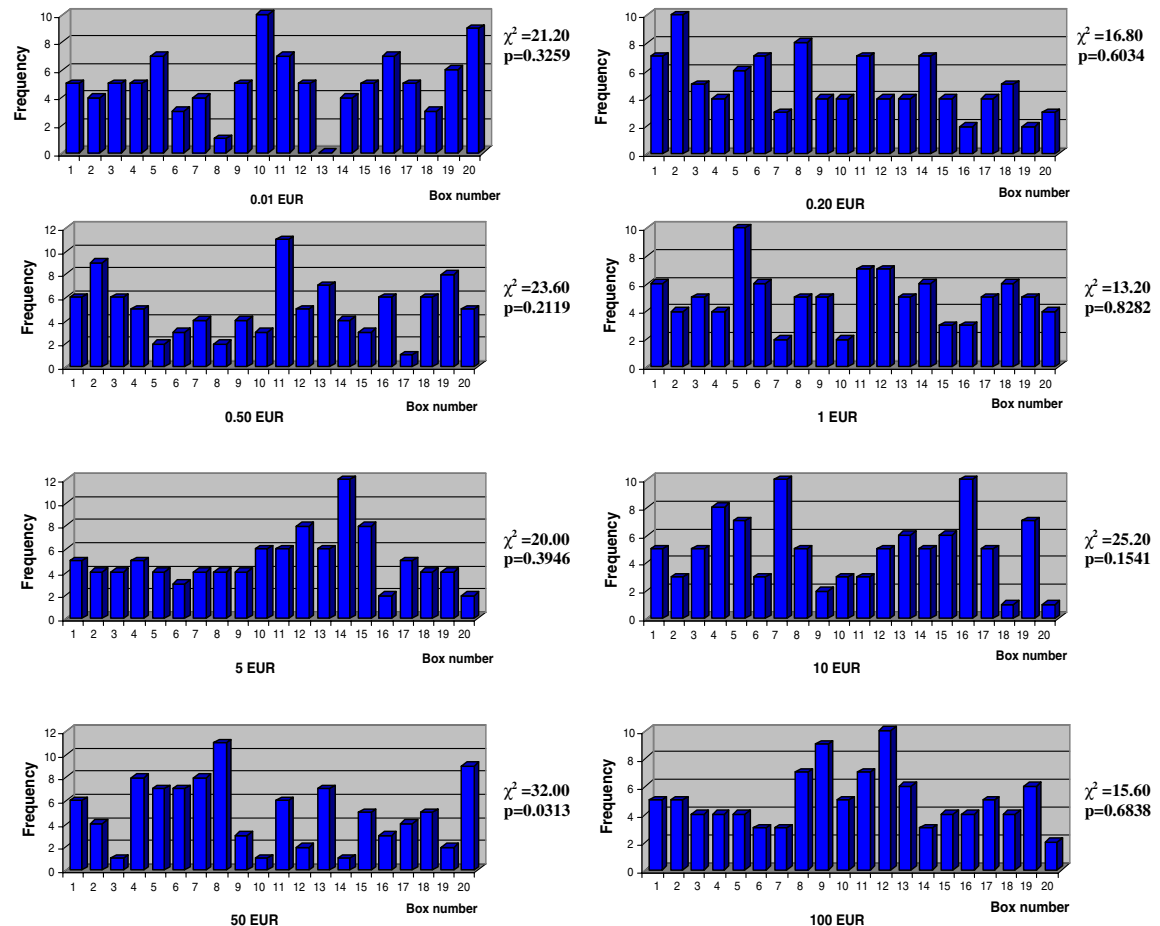

$\chi^{2}=\mathbf{2 0 . 0 0}$ $\mathrm{p}=\mathbf{0 . 3 9 4 6}$
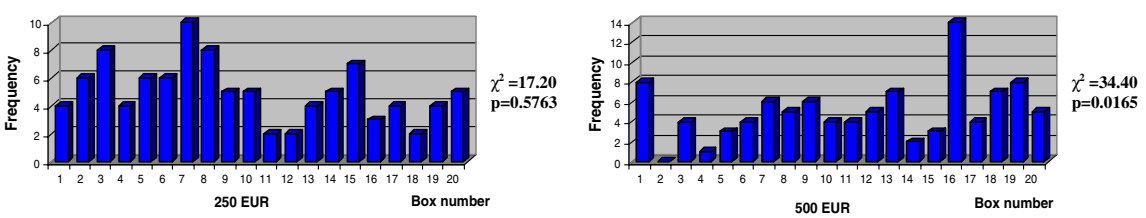

Fig. 4 The distribution of prizes from 0.01 to 500 Euros across 20 boxes

Consider a contestant who is offered an exchange when there are $N$ sealed boxes each containing one of the prizes $x_{1}<x_{2}<\cdots<x_{N}$. If an individual keeps her box, she obtains expected utility $\frac{1}{N} \sum_{i=1}^{N} u\left(w+x_{i}\right)$, where $u(\cdot)$ is a von 

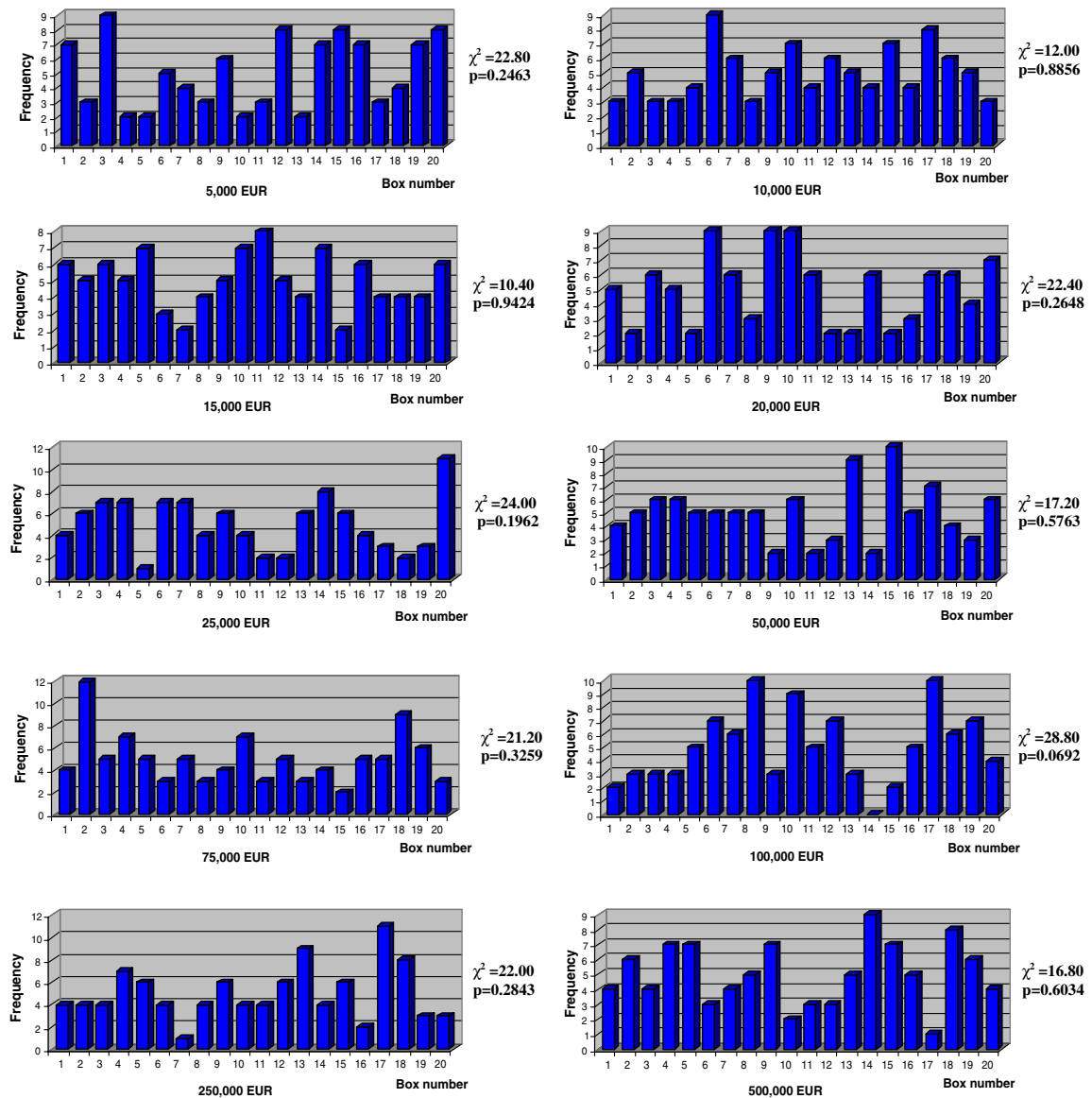

Fig. 5 The distribution of prizes from 5,000 to 500,000 Euros across 20 boxes

Neumann-Morgenstern utility function of the contestant and $w$ is her private wealth.

If the contestant exchanges her box that contains prize $x_{i}, i \in\{1, \ldots, N\}$, for one of the remaining sealed boxes, she obtains expected utility $\frac{1}{N-1} \sum_{j=1}^{N} u\left(w+x_{j}\right)$. The contestant does not know the content of her box and any prize $x_{1}, \ldots, x_{N}$ is equally likely to be inside her box. Therefore, after exchanging the boxes, the contestant receives expected utility $\frac{1}{N} \sum_{i=1}^{N} \frac{1}{N-1} \sum_{\substack{j=1 \\ j \neq i}}^{N} u\left(w+x_{j}\right)=\frac{1}{N(N-1)} \sum_{i=1}^{N}\left(\sum_{j=1}^{N}\right.$ $\left.u\left(w+x_{j}\right)-u\left(w+x_{i}\right)\right)=\frac{1}{N} \sum_{i=1}^{N} u\left(w+x_{i}\right)$. Thus, the contestant receives exactly the same expected utility after exchanging her box as after keeping her initial box. In other words, according to expected utility theory, there is no reason why the contestant should accept or reject an offer to exchange her box for one of the remaining sealed boxes. 


\subsubsection{Regret theory}

Many generalized non-expected utility theories also predict that an individual is indifferent between accepting and rejecting swap offer. For example, according to the regret theory, an individual always accepts exchange offer if $\frac{1}{N(N-1)} \sum_{i=1}^{N} \sum_{j=1}^{N} \psi$ $j \neq i$ $\left(x_{i}, x_{j}\right)>0$, where $\psi(\cdot, \cdot)$ is a skew-symmetric utility function, i.e., $\psi\left(x_{i}, x_{j}\right)=$ $-\psi\left(x_{j}, x_{i}\right)$ (e.g., Loomes and Sugden 1987). It is easy to see that $\sum_{i=1}^{N} \sum_{j=1}^{N} \psi$ $\left(x_{i}, x_{j}\right)=\sum_{i=2}^{N} \sum_{j=1}^{i-1} \psi\left(x_{i}, x_{j}\right)+\sum_{i=1}^{N-1} \sum_{j=i+1}^{N} \psi\left(x_{i}, x_{j}\right)=\sum_{i=2}^{N} \sum_{j=1}^{i-1} \psi\left(x_{i}, x_{j}\right)$ $-\sum_{j=i+1}^{N} \sum_{i=1}^{N-1} \psi\left(x_{j}, x_{i}\right)=0$. Thus, according to the regret theory, a contestant is exactly indifferent between accepting and rejecting the exchange offer. The intuition behind this result is simple. A contestant who accepts the exchange offer experiences ex post regret when she discovers at the end of the show that her initial box contained a larger prize. However, a contestant who rejects the exchange offer experiences exactly the same ex post regret when she opens all the boxes only to discover that her initial box contains a smaller prize than one of the boxes that she could have selected when the bank offered an exchange.

\section{1 .3 (Cumulative) prospect theory}

In prospect theory, an individual derives utility from changes in her asset position relative to a reference point (e.g., Kahneman and Tversky 1979). Prospect theory does not specify what constitutes a reference point in a particular decision problem. In this section, we show that an individual should never exchange her own box for any of the remaining sealed boxes irrespective of the location of a reference point. This theoretical prediction is driven by the assumption of loss aversion.

A contestant who rejects the exchange offer and keeps her box derives zero utility, since her asset position does not change (relative to any reference point). Now consider a contestant who accepts the exchange offer. Let $w$ be her private wealth (excluding the content of her box) and let $x_{i}, i \in\{1, \ldots, N\}$, denote a prize inside her box before exchange. Let $v($.$) be the value function that measures utility from$ changes in wealth relative to a reference point. The value function is normalized so that $v(0)=0$. Prospect theory assumes that individuals are loss averse, so that the value function is steeper for losses than for gains, i.e., $v(x)<-v(-x)$ for any $x>0$ (e.g., Kahneman and Tversky 1979).

Although prospect theory does not specify the location of a reference point, it assumes that individuals incorporate their initial endowments into their reference point (e.g., Kahneman et al. 1991; Tversky and Kahneman 1991). ${ }^{13}$ Thus, in the context of

\footnotetext{
13 Notice that if a contestant swaps boxes due to her subjective belief that her initial box contains a low prize, she may be expected to open an old box immediately after exchange. Interestingly, $90 \%$ of the contestants who accepted the exchange offer in the Italian version of Deal or No Deal, do not open their old box immediately after exchange. Contestants who accepted the first exchange offer opened on average 5.6 boxes before they called their old box to be opened. This may suggest that Italian contestants developed a sense of ownership and incorporated the content of their initial endowment into their reference point.
} 
this natural experiment, we can write a reference point as $r+x_{i}$, where $r$ is constant. Notice that $r=w$ is a special case corresponding to the original version of the prospect theory in Kahneman and Tversky (1979), where a reference point is assumed to be equal to a current asset position. A recently proposed model of Koszegi and Rabin (2006) corresponds to a special case when constant $r$ equals to the private wealth of a contestant $w$ plus her (unobservable) rational expectation of future earnings in Deal or No Deal. In the remainder of the article, we will assume that $r \geq w$.

According to the cumulative prospect theory, a contestant who exchanges her own box with prize $x_{i}$ for a box with a lower prize $x_{j}, j \in\{1, \ldots, i-1\}$ obtains utility $\sum_{j=1}^{i-1} v\left(w+x_{j}-r-x_{i}\right) \cdot\left[w_{-}\left(\operatorname{Pr}\left(\delta \leq w+x_{j}-r-x_{i}\right)\right)-w_{-}\left(\operatorname{Pr}\left(\delta<w+x_{j}-\right.\right.\right.$ $\left.\left.\left.r-x_{i}\right)\right)\right]$, where $w_{-}:[0,1] \rightarrow[0,1]$ is the probability weighting function for losses (Tversky and Kahneman 1991) and $\operatorname{Pr}\left(\delta<w+x_{j}-r-x_{i}\right)$ denotes the probability that the change in wealth $\delta$ during the swap of boxes (relative to a reference point $\left.r+x_{i}\right)$ is lower than $w+x_{j}-r-x_{i}$.

Finally, according to the cumulative prospect theory, a contestant who exchanges her own box with prize $x_{i}$ for a box with a higher prize $x_{j}, j \in\{i+1, \ldots, N\}$ obtains utility $\sum_{j=i+1}^{N} v\left(w+x_{j}-r-x_{i}\right) \cdot\left[w_{+}\left(\operatorname{Pr}\left(\delta \geq w+x_{j}-r-x_{i}\right)\right)-w_{+}(\operatorname{Pr}(\delta>w+\right.$ $\left.\left.\left.x_{j}-r-x_{i}\right)\right)\right]$, where $w_{+}:[0,1] \rightarrow[0,1]$ is the probability weighting function for gains. The contestant does not know the prize $x_{i}$ sealed inside her box, but she knows that each prize $x_{1}, \ldots, x_{N}$ is likely to be inside her box. Effectively, she has a stochastic reference point, and her ex ante utility from exchanging the boxes is given by

$$
\begin{aligned}
U= & \sum_{i=1}^{N} \sum_{j=1}^{i-1} v\left(w+x_{j}-r-x_{i}\right) \cdot\left[w_{-}\left(\operatorname{Pr}\left(\delta \leq w+x_{j}-r-x_{i}\right)\right)\right. \\
& \left.-w_{-}\left(\operatorname{Pr}\left(\delta<w+x_{j}-r-x_{i}\right)\right)\right]+\sum_{i=1}^{N} \sum_{j=i+1}^{N} v\left(w+x_{j}-r-x_{i}\right) \\
& \cdot\left[w_{+}\left(\operatorname{Pr}\left(\delta \geq w+x_{j}-r-x_{i}\right)\right)-w_{+}\left(\operatorname{Pr}\left(\delta>w+x_{j}-r-x_{i}\right)\right)\right] \\
& \text { or, equivalently,by } \\
U= & \sum_{i=1}^{N} \sum_{j=1}^{i-1}\left\{v ( x _ { j } - x _ { i } + w - r ) \cdot \left[w_{-}\left(\operatorname{Pr}\left(\delta \leq x_{j}-x_{i}+w-r\right)\right)\right.\right. \\
& \left.-w_{-}\left(\operatorname{Pr}\left(\delta<x_{j}-x_{i}+w-r\right)\right)\right]+v\left(x_{i}-x_{j}+r-w\right) \\
& \cdot\left[w_{+}\left(\operatorname{Pr}\left(\delta \geq x_{i}-x_{j}+r-w\right)-w_{+}\left(\operatorname{Pr}\left(\delta>x_{i}-x_{j}+r-w\right)\right)\right]\right\}
\end{aligned}
$$

Since all the prizes are randomly distributed across the boxes, when two boxes are exchanged, every positive change in wealth is equally likely as a negative change in wealth of the same absolute amount (relative to the same reference point). In other words, $\operatorname{Pr}\left(\delta \geq x_{i}-x_{j}+r-w\right)=\operatorname{Pr}\left(\delta \leq x_{j}-x_{i}+w-r\right)$ and $\operatorname{Pr}\left(\delta>x_{i}-x_{j}+\right.$ $r-w)=\operatorname{Pr}\left(\delta<x_{j}-x_{i}+w-r\right)$ for every $x_{i}>x_{j}$ and $r \geq w$. The assumption of 
loss aversion additionally implies that $v\left(x_{i}-x_{j}+r-w\right)<-v\left(x_{j}-x_{i}+w-r\right)$ for every $x_{i}>x_{j}$ and $r \geq w$. Using these two results, we can rewrite Eq. 1 as an inequality

$$
\begin{aligned}
& U<\sum_{i=1}^{N} \sum_{j=1}^{i-1} v\left(x_{j}-x_{i}+w-r\right) \cdot\left[w_{-}\left(\operatorname{Pr}\left(\delta \leq x_{j}-x_{i}+w-r\right)\right)\right. \\
& -w_{-}\left(\operatorname{Pr}\left(\delta<x_{j}-x_{i}+w-r\right)\right)-w_{+}\left(\operatorname{Pr}\left(\delta \leq x_{j}-x_{i}+w-r\right)\right) \\
& \left.+w_{+}\left(\operatorname{Pr}\left(\delta<x_{j}-x_{i}+w-r\right)\right)\right]
\end{aligned}
$$

Previous experimental studies demonstrate that the probability weighting function typically has a similar shape for gains and losses, but it is more curved for gains and more linear for losses (e.g., Tversky and Kahneman 1991; Abdellaoui 2000). We will assume that there exists probability $q \leq 1 / 2$ such that $w_{+}(p+\varepsilon)-$ $w_{+}(p) \geq w_{-}(p+\varepsilon)-w_{-}(p)$ for any $p, p+\varepsilon \in[0, q]$ and $w_{+}(p+\varepsilon)-w_{+}(p) \leq$ $w_{-}(p+\varepsilon)-w_{-}(p)$ for any $p, p+\varepsilon \in[q, 1]$. Inequality (2) then immediately implies that $U<0$, i.e., the contestant derives a strictly negative utility from exchanging her box for one of the remaining sealed boxes. In other words, according to the prospect theory, an individual has a strong reason not to exchange her box: the value of exchange is strictly negative because a loss averse individual expects more aggravation from losses than the pleasure from gains of the same amount.

\subsection{Dynamic decision problem}

In a dynamic decision problem, contestants take into account future "bank" offers that they are likely to receive in course of the game. A contestant facing prizes $x_{1}$ and $x_{2}$ hidden in two unopened boxes perceives them as a risky lottery $L\left(x_{1}, 1 / 2 ; x_{2}, 1 / 2\right)$ just as in a static decision problem. ${ }^{14}$ The contestant facing prizes $\mathbf{x}=\left\{x_{1}, \ldots, x_{N}\right\}$ hidden in $N>2$ unopened boxes perceives them as a risky lottery $L(\mathbf{x})$. Let $m$ denote the number of boxes that the contestant has to open before the next "bank" offer is made ( $m$ is either 2 or 3 in the French version, $m$ is either 1 or 3 in the Italian version, and $m=3$ in the British version of Deal or No Deal). There are $C_{N-m}^{N}=N ! /(m !(N-m) !)$ combinations of prizes $\mathbf{x}$ that the contestant can face when the next offer is made. Let us denote these combinations by $\mathbf{x}_{1}, \ldots, \mathbf{x}_{\mathbf{C}_{\mathbf{N}-\mathbf{m}}^{\mathrm{N}}}$. Lottery $L(\mathbf{x})$ is then recursively defined by

$$
\begin{aligned}
& L(\mathbf{x})=\frac{1-\hat{\pi}_{N-m}}{C_{N-m}^{N}} \sum_{i=1}^{C_{N-m}^{N}}\left[L\left(\mathbf{x}_{i}\right) I\left(u\left(L\left(\mathbf{x}_{i}\right)\right) \geq u\left(\hat{O}\left(\mathbf{x}_{i}\right)\right)\right)\right. \\
& \left.+\hat{O}\left(\mathbf{x}_{i}\right) I\left(u\left(L\left(\mathbf{x}_{i}\right)\right)<u\left(\hat{O}\left(\mathbf{x}_{i}\right)\right)\right)\right]+\frac{\hat{\pi}_{N-m}}{C_{N-m}^{N}} \sum_{i=1}^{C_{N-m}^{N}} L\left(\mathbf{x}_{i}\right),
\end{aligned}
$$

\footnotetext{
14 In French, Italian, and British versions of Deal or No Deal, the "bank" does not make any further monetary offers when a monetary offer for two prizes is rejected. Thus, in this case, dynamic and static decision problems coincide because there are no anticipated "bank" offers in the future.
} 
where $\hat{O}\left(\mathbf{x}_{i}\right)$ is the expectation of a future monetary offer for $\mathbf{x}_{i}$ prizes left in the unopened boxes, $\hat{\pi}_{N-m}$ is the expected probability that the "bank" offers an exchange option instead of a monetary amount at the stage when $N-m$ boxes remain unopened and $I(x)$ is an indicator function, i.e., $I(x)=1$ if $x$ is true and $I(x)=0$ if $x$ is false. ${ }^{15}$ For the sake of our argument, an anticipated future offer $\hat{O}\left(\mathbf{x}_{i}\right)$ can be either a probability distribution over possible monetary amounts or a monetary amount for certain.

\subsubsection{Expected utility theory}

Consider a contestant who is offered an exchange when there are $N$ sealed boxes with remaining prizes $\mathbf{x}=\left\{x_{1}, \ldots, x_{N}\right\}$. If $N=2$, this contestant obtains expected utility $u(L(\mathbf{x}))=u\left(w+x_{1}\right) / 2+u\left(w+x_{2}\right) / 2$ from rejecting the exchange offer. If $N>2$, utility from rejecting the swap offer can be calculated through a Bellman optimality equation

$$
\begin{aligned}
& u(L(\mathbf{x}))=\frac{1}{C_{N-m}^{N}} \sum_{i=1}^{C_{N-m}^{N}}\left[\left(1-\hat{\pi}_{N-m}\right) \max \left\{u\left(L\left(\mathbf{x}_{i}\right)\right), u\left(\hat{O}\left(\mathbf{x}_{i}\right)\right)\right\}\right. \\
& \left.+\hat{\pi}_{N-m} u\left(L\left(\mathbf{x}_{i}\right)\right)\right] .
\end{aligned}
$$

Now consider the case when the contestant exchanges her old box for the new box with prize $x_{j}, j \in\{1, \ldots, N\}$ sealed inside. If $N=2$, this contestant obtains expected utility $u(L(\mathbf{x}))=u\left(w+x_{1}\right) / 2+u\left(w+x_{2}\right) / 2$ after accepting the exchange offer. If $N>2$, there are $C_{N-1-m}^{N-1}=(N-1) ! /(m !(N-1-m) !)=C_{N-m}^{N} / N$ combinations of prizes $\mathbf{x}$, all of which include prize $x_{j}$, that the contestant can face when the next offer is made. Let us denote these combinations by $\left.\mathbf{x}_{1}\right|_{x_{j}}, \ldots, \mathbf{x}_{\mathbf{C}_{\mathbf{N}-\mathbf{m}}^{\mathbf{N}}} /\left.\mathbf{N}\right|_{x_{j}}$. Utility from accepting the exchange offer (conditional on the prize $x_{j}$ being inside the new box) is then given by Bellman equation

$$
\begin{aligned}
u\left(L\left(\left.\mathbf{x}\right|_{x_{j}}\right)\right)= & \frac{N}{C_{N-m}^{N}} \sum_{i=1}^{C_{N-m}^{N} / N}\left[\left(1-\hat{\pi}_{N-m}\right) \max \left\{u\left(L\left(\left.\mathbf{x}_{i}\right|_{x_{j}}\right)\right), u\left(\hat{O}\left(\left.\mathbf{x}_{i}\right|_{x_{j}}\right)\right)\right\}\right. \\
& \left.+\hat{\pi}_{N-m} u\left(L\left(\left.\mathbf{x}_{i}\right|_{x_{j}}\right)\right)\right]
\end{aligned}
$$

Since the contestant does not know which prize is sealed inside her new box and prizes are distributed across boxes at random, expected utility after accepting exchange is given by $\frac{1}{N} \sum_{j=1}^{N} u\left(L\left(\left.\mathbf{x}\right|_{x_{j}}\right)\right)$, where conditional expected utility $u\left(L\left(\left.\mathbf{x}\right|_{x_{j}}\right)\right)$

\footnotetext{
15 For any two lotteries, $L_{1}\left(y_{1}, p_{1} ; \ldots ; y_{k}, p_{k}\right)$ and $L_{2}\left(z_{1}, q_{1} ; \ldots ; z_{l}, q_{l}\right)$ a compound lottery $\alpha L_{1}+$ $(1-\alpha) L_{2}, \alpha \in[0,1]$, is defined in the usual way-it yields outcome $y_{i}$ with probability $\alpha \cdot p_{i}, i \in$ $\{1, \ldots, k\}$, and outcome $z_{j}$ with probability $(1-\alpha) \cdot q_{j}, j \in\{1, \ldots, l\}$.
} 
is defined in (5). Notice that $\bigcup_{j=1}^{N}\left\{\left.\mathbf{x}_{\mathbf{1}}\right|_{x_{j}}, \ldots,\left.\mathbf{x}_{\mathbf{C}_{\mathbf{N}-\mathbf{m}}^{\mathbf{N}} / \mathbf{N}}\right|_{x_{j}}\right\}=\left\{\mathbf{x}_{\mathbf{1}}, \ldots, \mathbf{x}_{\mathbf{C}_{\mathbf{N}-\mathbf{m}}^{\mathbf{N}}}\right\}$ and expected utility after accepting exchange offer can be re-written as (4). Thus, in a dynamic decision problem, expected utility maximizer gets the same utility from accepting and from rejecting exchange offer.

\subsection{2 (Cumulative) prospect theory}

In a dynamic decision problem, similar to a static decision problem, contestants obtain zero utility from rejecting the exchange offer because their asset position does not change relative to any reference point that they may adopt. Next, we show that contestants receive a strictly negative utility from accepting the exchange offer. If there are only two unopened boxes left with prizes $x_{1}$ and $x_{2}$ sealed inside, a contestant, who accepts the exchange offer, derives utility $v\left(w+x_{1}-r-x_{2}\right) w_{-}(1 / 2)+$ $v\left(w+x_{2}-r-x_{1}\right) w_{+}(1 / 2)<-v\left(r+x_{2}-w-x_{1}\right) w_{-}(1 / 2)+v\left(w+x_{2}-\right.$ $\left.r-x_{1}\right) w_{+}(1 / 2) \leq v\left(r+x_{2}-w-x_{1}\right)\left[w_{+}(1 / 2)-w_{-}(1 / 2)\right] \leq 0$, with the first (strict) inequality due to the assumption of loss aversion.

If there are $N>2$ unopened boxes left, a contestant faces a lottery recursively defined by (3). Notice that we cannot write Bellman Eq. 4 because (cumulative) prospect theory does not satisfy the independence axiom of expected utility theory. Let $L\left(z_{1}, p_{1} ; \ldots ; z_{M}, q_{M}\right)$ denote the reduced form of a compound lottery, which is recursively defined in (3). According to (cumulative) prospect theory, utility of this lottery is given by

$$
\begin{aligned}
U= & \sum_{i=1}^{N} \sum_{\substack{j=1 \\
z_{j}<x_{i}}}^{M} v\left(w+z_{j}-r-x_{i}\right) \cdot\left[w_{-}\left(\operatorname{Pr}\left(\delta \leq w+z_{j}-r-x_{i}\right)\right)\right. \\
& \left.-w_{-}\left(\operatorname{Pr}\left(\delta<w+z_{j}-r-x_{i}\right)\right)\right]+\sum_{i=1}^{N} \sum_{\substack{j=1 \\
z_{j}>x_{i}}}^{M} v\left(w+z_{j}-r-x_{i}\right) \\
& \cdot\left[w_{+}\left(\operatorname{Pr}\left(\delta \geq w+z_{j}-r-x_{i}\right)\right)-w_{+}\left(\operatorname{Pr}\left(\delta>w+z_{j}-r-x_{i}\right)\right)\right] .
\end{aligned}
$$

If prizes are distributed across boxes at random and contestants' expectation of future monetary offers depends only on the set of possible prizes, ${ }^{16}$ every positive change in wealth during the swap is equally likely as a negative change in wealth of the same absolute amount (relative to the same reference point). Following the derivation presented in Sect. 4.1.3, we can easily show that $U<0$ due to the assumption of loss aversion.

\footnotetext{
16 Deck et al. (2008); Post et al. (2008), and Blavatskyy and Pogrebna $(2008,2009)$ all report that "bank" monetary offers depend only on the distribution of possible prizes (in particular, the expected value of possible prizes). Bombardini and Trebbi (2005) also find strong correlation between the expected value of possible prizes and "bank" monetary offers.
} 
Table 2 Decisions of contestants on the first (or only) exchange offer

\begin{tabular}{llll}
\hline Decision on the first (or the only) exchange offer & \multicolumn{3}{l}{ Number (percentage) of episodes } \\
\cline { 2 - 4 } & French version & Italian version & British version \\
\hline Accept & $19(46 \%)$ & $40(40 \%)$ & $27(43 \%)$ \\
Reject & $22(54 \%)$ & $60(60 \%)$ & $36(57 \%)$ \\
\hline
\end{tabular}

Table 3 Decisions of contestants on the second exchange offer

\begin{tabular}{lllr}
\hline $\begin{array}{l}\text { Decision on the first } \\
\text { exchange offer }\end{array}$ & $\begin{array}{c}\text { Decision on the second } \\
\text { exchange offer }\end{array}$ & \multicolumn{2}{l}{ Number (percentage) of episodes } \\
\cline { 3 - 4 } & & French version & Italian version \\
\hline Accept & Accept & $1(4 \%)$ & $3(11 \%)$ \\
\multirow{2}{*}{ Reject } & Reject & $12(44 \%)$ & $8(28 \%)$ \\
& Accept & $11(41 \%)$ & $7(25 \%)$ \\
& Reject & $3(11 \%)$ & $10(36 \%)$ \\
\hline
\end{tabular}

\section{Results}

Tables 2 and 3 show the decisions of contestants on the first (or the only) exchange offer and the second exchange offer, respectively. The second swap opportunity is offered only in French and Italian versions of Deal or No Deal. It is accepted in 45\% of the cases in the French version and in $36 \%$ of the cases in the Italian version. Observed decisions are quite similar across all the three versions even through French contestants typically receive several swap offers, Italian contestants are guaranteed to get at least one exchange opportunity and only one fifth of the British contestants are given the chance to swap boxes.

High percentage of contestants, who accept the exchange offer and do not keep their initial endowment, shows that contestants exhibit rather weak endowment effects. Contestants who accept at least one exchange offer do not reveal endowment effects. Contestants who rejected all the swap offers do not necessarily exhibit an endowment effect. Thus, contestants who accept the first (or the only) exchange offer, and contestants who reject the first offer but accept the second offer are not averse to losses. 73\% of French contestants, $47 \%$ of Italian contestants, and $43 \%$ of British contestants who have receive the exchange offer in our dataset, clearly reveal no endowment effect. ${ }^{17}$

Expected utility theory and many non-expected utility theories (e.g., regret theory) predict that an individual is exactly indifferent between accepting and rejecting the swap. The chi-squared statistics for the null hypothesis that contestants accept the exchange offer with probability 50\% are $\chi^{2}=0.286(p=0.593), \chi^{2}=2.722(p=$ $0.099)$, and $\chi^{2}=1.286(p=0.257)$, respectively, for French, Italian, and British contestants, who received only one exchange offer. Thus, these contestants appear to

17 In the French (Italian) version of Deal or No Deal, 19 (40) contestants accept the first offer and 11 (7) contestants reject the first offer, but accept the second offer. Thus, 30 out of 41 French contestants (73\%) and 47 out of 100 Italian contestants (47\%), who receive the swap offer, accept at least one exchange offer. 
Table 4 Decisions of French contestants on the third exchange offer

\begin{tabular}{|c|c|c|c|c|c|c|c|c|}
\hline First exchange & Accept & & & & Reject & & & \\
\hline Second exchange & Accept & & Reject & & Accept & & Reject & \\
\hline Third exchange & Accept & Reject & Accept & Reject & Accept & Reject & Accept & Reject \\
\hline Number $(\%)$ of episodes & $0(0 \%)$ & $0(0 \%)$ & $3(16 \%)$ & $4(21 \%)$ & $2(10.5 \%)$ & $8(42 \%)$ & $0(0 \%)$ & $2(10.5 \%)$ \\
\hline
\end{tabular}

be largely indifferent between accepting and rejecting the swap. However, in all the three versions, a higher proportion of contestants reject the swap offer. This is consistent with certain degree of "stickiness" that Friedman (1998) finds in the Monty Hall problem and with the "reluctance to switch" that Charness and Levin (2005) observe in a simple Bayesian updating game.

For contestants who received two exchange offers, the chi-squared statistics are $\chi^{2}=13.741(p=0.003)$ and $\chi^{2}=3.714(p=0.294)$, respectively, in the French and Italian versions. Thus, the hypothesis that these contestants are equally likely to accept or reject the swap cannot be rejected in the Italian dataset, but it is rejected at $1 \%$ significance level in the French dataset. To shed more light on this finding, consider the decisions of 19 French contestants who have received three exchange offers (Table 4). The frequency of these decisions is significantly different from a uniform distribution $\left(\chi^{2}=21.842, p=0.003\right)$.

An inspection of Tables 3 and 4 reveals that Deal or No Deal contestants tend to accept one exchange offer, but they are reluctant to swap boxes several times even if the exchange opportunity is persistently repeated. ${ }^{18}$ Thus, multiple exchange opportunities increase the number of contestants who swap boxes once (in violation of the endowment effect). However, multiple exchange opportunities cause no sizable increase in the number of contestants who swap boxes more than once (in violation of the assumption that contestants are equally likely to accept and to reject the exchange offer).

Approximately every second contestant who receives the exchange offer swaps the boxes at least once. Thus, observed endowment effects are weaker in our recorded sample compared with typical findings in the laboratory experiments. However, if preferences or decision-making rules are heterogeneous, our results may suggest that while most contestants are indifferent to accepting the exchange offer, some of them exhibit endowment effects. Another possibility could be that people are generally loss averse when boxes contain large prizes, but they are largely indifferent between accepting and rejecting the swap if large prizes are eliminated from the game. In order to investigate these hypotheses, we regress exchange decisions on lottery-specific (expected value, median, and standard deviation of possible prizes, etc.) and individual-specific variables (gender, age, and marital status). Maximum likelihood logit coefficient estimates (and standard errors) are reported in Table 5.

18 Our sample also includes four French contestants who received four exchange offers during the game. Among these contestants, one contestant rejected all the four offers, two contestants accepted one exchange offer, and the remaining contestants swapped boxes twice. 
Table 5 Estimated coefficients (standard errors) in a logit regression of exchange decisions (dependant variable is 1 if contestant swaps boxes and 0 otherwise)

\begin{tabular}{|c|c|c|c|}
\hline $\begin{array}{l}\text { Explanatory } \\
\text { variables }\end{array}$ & French version & Italian version & British version \\
\hline Constant & $5.7326(4.4159)$ & $0.3027(2.1527)$ & $4.2688(2.6896)$ \\
\hline $\begin{array}{l}\text { Natural logarithm of expected } \\
\text { value of possible prizes }\end{array}$ & $-0.7766(1.2433)$ & $0.1300(1.0588)$ & $0.7133(1.4368)$ \\
\hline $\begin{array}{l}\text { Natural logarithm of a } \\
\text { median possible prize }\end{array}$ & $-0.0635(0.1845)$ & $0.0827(0.1636)$ & $0.3959(0.6906)$ \\
\hline $\begin{array}{l}\text { Natural logarithm of a } \\
\text { standard deviation of } \\
\text { possible prizes }\end{array}$ & $0.4124(1.1894)$ & $0.0078(0.9682)$ & $-1.2981(0.9610)$ \\
\hline $\begin{array}{l}\text { Number of "large" prizes left } \\
\text { in the list of possible prizes" }\end{array}$ & $-0.1145(0.1294)$ & $-0.0919(0.1421)$ & $0.2114(0.3353)$ \\
\hline $\begin{array}{l}\text { Gender dummy ( } 0 \text { for male, } 1 \\
\text { for female) }\end{array}$ & $-0.2466(0.5656)$ & $-0.7332(0.3937)$ & $-0.7499(0.6000)$ \\
\hline $\begin{array}{l}\text { Self-reported age or an } \\
\text { estimate based on a physical } \\
\text { appearance (in years) }\end{array}$ & $-0.0048(0.0516)$ & $-0.0297(0.0169)$ & $-0.0255(0.0247)$ \\
\hline $\begin{array}{l}\text { Marital status ( } 1 \text { for married, } \\
2 \text { for single, } 3 \text { for divorced, } \\
4 \text { for widowed) }\end{array}$ & $-0.2628(0.4820)$ & $-0.4354(0.3286)$ & $-1.1338(0.9728)$ \\
\hline $\begin{array}{l}\text { Dummy variable ( }=1 \text { if a } \\
\text { contestant already accepted } \\
\text { an earlier swap offer) }\end{array}$ & $-1.6023(0.6282)$ & $-0.5723(0.8508)$ & - \\
\hline Number of observations $N$ & 91 & 129 & 63 \\
\hline Log-likelihood & -55.0224 & -81.5361 & -37.4887 \\
\hline $\begin{array}{l}\text { McFadden's likelihood ratio } \\
\text { index }\end{array}$ & 0.1277 & 0.0881 & 0.1415 \\
\hline Veall and Zimmermann $R^{2}$ & 0.2589 & 0.1874 & 0.2823 \\
\hline
\end{tabular}

a"Large" prizes are defined as prizes that appear on the right-hand side of a television screen. "Large" prizes are prizes greater than $€ 5000$ in French version, greater than $€ 500$ in Italian version, and greater than $£ 750$ in British version

Table 5 shows that exchange decisions do not depend on the distribution of possible monetary prizes that contestants face when the "bank" offers a swap opportunity. Contestants, who eliminated large prizes, do not appear to be significantly more likely to accept or reject the exchange offer compared to contestants who eliminated small prizes. Similarly, contestants' decision to accept the exchange offer is apparently not affected by the expected value, median, or standard deviation of prizes that are left in unopened boxes.

Table 5 also shows no evidence of exchange decisions being correlated with individual-specific variables (only in the Italian version of Deal or No Deal female, and older contestants are marginally less likely to accept a swap offer). Overall, none of lottery-specific or individual-specific variables has a significant explanatory power for predicting the decisions to accept the exchange offer. ${ }^{19}$ Such decisions appear to be

19 The only variable that is statistically significant (in the French version of Deal or No Deal) is a dummy variable indicating whether a contestant already accepted a swap offer earlier in the course of the show. 
quite random and spontaneous, perhaps indicating that contestants are indeed largely indifferent between accepting and rejecting the swap offer.

\section{Conclusion}

Television show Deal or No Deal offers a unique opportunity to study individual decision making under risk using lotteries with outcomes as high as half a million euros. Perhaps for the first time since the famous thought experiment of Maurice Allais, we can investigate choice between large-stake lotteries with real incentives and real people. Contestants from various regions of France, Italy, and United Kingdom are widely dispersed in terms of age and occupation, which makes them a more diversified subject pool compared to the undergraduate students in the conventional laboratory experiments.

Deal or No Deal contestants are endowed with a sealed box containing unknown monetary prize (drawn from a known uniform distribution). In French, Italian, and British versions of Deal or No Deal, contestants can exchange their initial endowment for an identical box with another prize drawn from the same uniform distribution. We find that $73 \%$ of French contestants, $47 \%$ of Italian contestants, and $43 \%$ of British contestants, who receive the possibility to swap their box, accept the exchange offer at least once. Thus, Deal or No Deal contestants reveal weaker endowment effects compared with typical findings in the laboratory experiments. These results suggest that even inexperienced individuals may overcome endowment effect when facing unusual decision problem involving substantial monetary rewards.

Exchange decisions are not correlated with lottery-specific variables such as the expected value of possible prizes. Contestants, who eliminated large prizes from the list of possible prizes, do not appear to be more likely to accept or reject the exchange offer. We also find that exchange decisions are not correlated with individualspecific variables, with the exception of Italian female and older contestants, who are marginally less likely to accept the exchange offer. Thus, if there are individual differences in the strength of endowment effects, they appear to be largely an unobserved heterogeneity.

In traditional laboratory studies of endowment effects (e.g., Plott and Zeiler 2007; List 2004; Knetsch 1989) subjects are endowed with physical goods of a similar value. In contrast, Deal or No Deal contestants receive uncertain endowments. The use of risky lotteries as the objects of exchange is a promising avenue for studying endowment effects when stakes are as high as half a million Euros. Commodities that have similar high value (e.g., real estate properties, Monet paintings from the same series, etc.) are never exactly identical with many small inconsequential differences (e.g., a view from the window).

An experimenter can hardly control for such differences that may be just sufficient for inducing a strict preference for one of the objects. However, an experimenter can always construct identical risky lotteries over cash prizes or physical goods. Laboratory studies show that the effects of loss aversion are just as strong in choice under risk as they are in a riskless choice (e.g., Tversky and Kahneman 1991). Thus, the research on the loss aversion and the endowment effect can benefit from further laboratory 
experiments on the exchange asymmetries when the objects of exchange are identical risky lotteries.

If contestants incorporate the (initially unknown) content of the box that they select for themselves at the beginning of the show into their reference point, then loss aversion predicts that contestants should always reject a swap offer. This is a stronger implication of loss aversion than that in the mug-candy bar exchange experiments (Knetsch and Sinden 1984; Samuelson and Zeckhauser 1988; Knetsch 1989). In these experiments, loss aversion implies that the fraction of individuals, who are not willing to exchange a mug (candy bar) for a candy bar (mug), should be higher in the treatment where subjects were initially endowed with a mug (candy bar) compared to the fraction of subjects in the baseline treatment, who were endowed with nothing and subsequently choose a mug (candy bar). Such control treatment is not required in our natural experiment because two objects that are exchanged yield identical distributions of monetary prizes.

Acknowledgements We are grateful to Colin Camerer and Richard Thaler for their advice and helpful suggestions. We thank Steffen Andersen, Daniela Di Cagno, Christian Ewerhart, Anita Gantner, Lorenz Goette, Glenn Harrison, John Hey, Rudolf Kerschbamer, Wolfgang Koehler, Morten Lau, Charles Plott, Ulrich Schmidt, Francesco Trebbi, Nathaniel Wilcox, and Peter Wakker for their comments. We also thank participants of research seminars at Humboldt University in Berlin (May 2007), the University of Zurich (December 2006), Max Planck Institute for Research on Collective Goods in Bonn (October 2006), the University of Bonn (September 2006), and the University of Innsbruck (May 2006), participants of the Augustin Cournot Doctoral Days in Strasbourg, France (April 2007), the Economic Science Association European Meeting in Nottingham, United Kingdom (September 2006) and the 12th International Conference on The Foundation and Application of Utility, Risk and Decision Theory in Rome, Italy (June 2006). We are grateful to Anabela Botelho and Glenn Harrison who generously provided data from the French version of Deal or No Deal. We have benefited from extensive discussions with, and helpful suggestions from, Thierry Post and Guido Baltussen. Pavlo Blavatskyy acknowledges financial support from the Fund for Support of Academic Development at the University of Zurich.

\section{References}

Abdellaoui, M. (2000). Parameter-free elicitation of utility and probability weighting functions. Management Science, 46, 1497-1512.

Blavatskyy, P., \& Pogrebna, G. (2008). Risk aversion when gains are likely and unlikely: Evidence from a natural experiment with large stakes. Theory and Decision, 64, 395-420

Blavatskyy, P., \& Pogrebna, G. (2009). Models of stochastic choice and decision theories: Why both are important for analyzing decisions. Journal of Applied Econometrics (forthcoming)

Bombardini, M., \& Trebbi, F. (2005). Risk aversion and expected utility theory: A field experiment with large and small stakes (unpublished manuscript)

Brookshire, D., \& Coursey, D. (1987). Measuring the value of a public good: An empirical comparison of elicitation procedures. American Economic Review, 77, 554-566.

Coursey, D., Hovis, J., \& Schulze, W. (1987). The disparity between willingness to accept and willingness to pay measures of value. Quarterly Journal of Economics, 102, 679-690.

Charness, G., \& Levin, D. (2005). When optimal choices feel wrong: A laboratory study of Bayesian updating, complexity, and affect. American Economic Review, 95, 1300-1309.

Deck, C., Lee, J., \& Reyes, J. (2008). Risk attitudes in large stakes gambles: Evidence from a game show. Applied Economics, 40 (1), 41-52.

Friedman, D. (1998). Monty Hall's three doors: Construction and deconstruction of a choice anomaly. American Economic Review, 88, 933-946

Kahneman D., Knetsch, J. L., \& Thaler, R. H. (1990). Experimental tests of the endowment effect and the Coase Theorem. Journal of Political Economy, 98, 25-48. 
Kahneman D., Knetsch J., \& Thaler, R. (1991). Anomalies: The endowment effect, loss aversion, and status quo bias. Journal of Economic Prospectives, 5(1), 193-206.

Kahneman, D., \& Tversky, A. (1979). Prospect theory: An analysis of decision under risk. Econometrica, 47, 263-291.

Knetsch, J. L. (1989). The endowment effect and evidence of nonreversible indifference curves. American Economic Review, 79(5), 1277-1284.

Knetsch, J. L., \& Sinden, J. A. (1984). Willingness to pay and compensation demanded: Expermental evidence of an unexpected disparity in measures of value. Quarterly Journal of Economics, 99(3), 507-521.

Knez, P., Smith, V. L., \& Williams, A. (1985). Individual rationality, market rationality, and value estimation. American Economic Review, 75, 397-402.

Koszegi, B. \& Rabin, M. (2006). A model of reference-dependent preferences. Quarterly Journal of Economics, 121(4), 1133-1165.

List, J. (2004). Neoclassical theory versus prospect theory: Evidence from the marketplace. Econometrica, $72(2), 615-625$.

Loomes, G., \& Sugden, R. (1987). Some applications of a more general form of regret theory. Journal of Economic Theory, 41, 270-287

Myagkov, M., \& Plott, Ch. R. (1997). Exchange economies and loss exposure: Experiments exploring prospect theory and competitive equilibria in market environments. American Economic Review, 87(5), 801-828.

Plott, Ch. R., \& Zeiler, K. (2007). Exchange asymmetries incorrectly interpreted as evidence of endowment effect theory and prospect theory? American Economic Review, 97, 1449.

Pogrebna, G. (2008). Naive advice when half-a-million is at stake. Economics Letters, 98(2), 148-154.

Post, T., Van den Assem, M., Baltussen, G., \& Thaler, R. (2008). Deal or no deal? Decision making under risk in a large-payoff game show. American Economic Review, 98(1), 38-71.

Samuelson, W., \& Zeckhauser, R. (1988). Status quo bias in decision making. Journal of Risk and Uncertainty, 1(1), 7-59.

Shogren, J. F., Shin, S. Y., Hayes, D. J., \& Kliebenstein, J. B. (1994). Resolving differences in willingness to pay and willingness to accept. American Economic Review, 84, 255-270.

Thaler, R. (1980). Toward a positive theory of consumer choice. Journal of Economic Behavior and Organization 1, 39-60.

Tversky, A., \& Kahneman, D. (1991). Loss aversion in riskless choice: A reference-dependent model. Quarterly Journal of Economics, 106, 1039-1061.

Tversky, A., \& Kahneman, D. (1992). Advances in prospect theory: Cumulative representation of uncertainty. Journal of Risk and Uncertainty, 5, 297-323. 